\title{
Influencing Factors Analysis and Trend Forecasting of China's Total Energy Consumption
}

\author{
Geng Wang ${ }^{1, a}$ \\ ${ }^{1}$ Department of Statistics, Nanjing University of Finance and Economics, Nanjing 210046, China \\ awgwgwg0912@126.com
}

Keywords: Energy Consumption, GM(1,1) Model, Gray Incidence Analysis.

Abstract. In order to answer following two questions, One is the influence factors and the influence degree of China's total energy consumption, Another is in the future five years China's total energy consumption trend prediction. This paper begins with a qualitative analysis of factors affecting China's total energy consumption, resulting in the classification of these factors according to their importance and significance by using the Grey Correlation Analysis method; Based on the fact China's total energy consumption system is gray, this paper established the Grey forecasting model GM (1, 1), 2015 2019 China's total energy consumption was forecast. This paper studies showed that China's total energy consumption is sub-health; As long as continue to strengthen the work of the use of natural gas, nuclear energy and renewable energy, in the next five years, Health controllable of China's total energy consumption will remain stable.

\section{Introduction}

In 2011, China's GDP surpassed Japan as the world's second-largest economy for the first time, GDP in 2015 reached $\$ 67.6708$ trillion, increased by $6.9 \%$ than in 2014, But China's economic growth is built on the basis of a large number of energy consumption, China's energy consumption has accounted for over $20 \%$ of the total global energy consumption, and more than the United States. The present China is facing both development and reasonable challenge to reduce the consumption of energy, So this article choose to study in China's energy consumption. Our problem is China's energy consumption of health? Main influencing factors of is what? Effect how? During the 13th Five-Year Plan period, What is the trend of China's energy consumption? By using the gray correlation method and GM $(1,1)$ model, We discuss two problems , One is the influence factors and the influence degree of China's total energy consumption, Another is in the future five years China's total energy consumption trend prediction.

\section{Gray Incidence Analysis of China's total energy consumption}

Consider, China's total energy consumption is a Grey system, Influence China's energy consumption, there are many factors. Using Grey correlation method to study the correlation factor to affect the size of China's energy consumption, Thus to provide evidence for policy of China's total energy consumption.

\section{Grey relational analysis.}

Grey relational analysis is the main content of gray system theory of one, it is the foundation of Gray system analysis, forecast and decision. It according to the analysis of Grey system behavior factor and the system related behavior factor's closely degree, to judge the system caused by the development of the main factors and secondary factors.

The basic idea is: according to the time sequence of the factors of the curve of similar degree, to judge the geometric relationships between factors are closely; Curve the geometric shape, corresponding to the correlation between the greater the sequence; Otherwise the small.

\section{Algorithm steps:}

Step 1. Sure Yo(reference sequence) and Yi(compare sequences); 
Step 2.For Reference sequence and the comparison sequence, do initialization;

Step 3.Calculating correlation coefficient:

$\gamma\left(Y_{0}(k), Y_{i}(k)\right)=\frac{\Delta_{\min }+\rho \cdot \Delta_{\max }}{\Delta_{o i}(k)+\rho \cdot \Delta_{\max }}$, here $\rho$ is distinguish coefficient, Usually, take for 0.5 ;

Step 4: correlation calculation : $\gamma\left(Y_{0}, Y_{i}\right)=\frac{1}{n} \sum_{k=1}^{n} \gamma\left(Y_{0}(k), Y_{i}(k)\right)$

Step 5: sort order

Index selection

Based on the national bureau of statistics annual data, Reference index choose the composition of coal, oil, natural gas and electricity. This paper will discuss the relevance respectively.

The empirical analysis

Collect data (1996 2014), the arrangement to table 1 (Data sources: The national bureau of statistics, the total energy consumption and composition in 1996-2014 communique )

Table 1 The total energy consumption and composition data of 1996-2014 Units: ten thousand tons of standard coal

\begin{tabular}{|c|c|c|c|c|c|}
\hline & $\mathrm{X} 1$ & $\mathrm{X} 2$ & $\mathrm{X} 3$ & $\mathrm{X} 4$ & $\mathrm{Y}$ \\
\hline 1996 & 99366 & 25281 & 2433 & 8112 & 135192 \\
\hline 1997 & 97039 & 27725 & 2446 & 8698 & 135909 \\
\hline 1998 & 96554 & 28326 & 2451 & 8852 & 136184 \\
\hline 1999 & 99242 & 30222 & 2811 & 8294 & 140569 \\
\hline 2000 & 100670 & 32332 & 3233 & 10728 & 146964 \\
\hline 2001 & 105772 & 32976 & 3733 & 13066 & 155547 \\
\hline 2002 & 116160 & 35611 & 3900 & 13905 & 169577 \\
\hline 2003 & 138352 & 39614 & 4533 & 14584 & 197083 \\
\hline 2004 & 161657 & 45826 & 5296 & 17501 & 230281 \\
\hline 2005 & 189231 & 46524 & 6273 & 19341 & 261369 \\
\hline 2006 & 207402 & 50132 & 7735 & 21199 & 286467 \\
\hline 2007 & 225795 & 52945 & 9343 & 23358 & 311442 \\
\hline 2008 & 229237 & 53542 & 10901 & 26931 & 320611 \\
\hline 2009 & 240666 & 55125 & 11764 & 28571 & 336126 \\
\hline 2010 & 249568 & 62753 & 14426 & 33901 & 360648 \\
\hline 2011 & 271704 & 65023 & 17804 & 32512 & 387043 \\
\hline 2012 & 275465 & 68363 & 19303 & 39007 & 402138 \\
\hline 2013 & 280999 & 71292 & 22096 & 42525 & 416913 \\
\hline 2014 & 281160 & 72846 & 24282 & 47712 & 426000 \\
\hline
\end{tabular}

where, Y、X1、X2、X3、X4 denote index of China's total energy consumption , the composition of coal, oil, natural gas and electricity power, respectively.

\section{Correlation between China's total energy consumption and four types of indicators}

According to the data table 1, The following correlation coefficients is obtained by using Data processing system (DPS) : $r(\mathrm{Y}, \mathrm{X} 1)=0.83955, r(\mathrm{Y}, \mathrm{X} 2)=0.76202 ; r(\mathrm{Y}, \mathrm{X} 3)=0.55780, r(\mathrm{Y}, \mathrm{X} 4)=0.67217$.

\section{Conclusion1:}

Surface the composition of coal, oil with China's total energy consumption index is the highest correlation, correlation value of $0.83955,0.76202$,respectively. The power consumption is the third, correlation value of 0.67217 . Explanation: Total power consumption of China's energy consumption also has a great role in promoting, The promoting function of gas consumption in China's energy consumption is the smallest.

\section{Conclusion2:}

On the whole, The correlation of China's total energy consumption index and gas consumption is the lowest, Correlation value was 0.55578 . This is not quite normal, according to the normal structure of energy consumption of developed countries, the correlation of gas consumption should be in the top three. And nuclear energy and renewable energy consumption also accounted for $4 \%$ to $8 \%$, So China's energy consumption depends on healthy growth to speed up the use of natural gas, nuclear energy and renewable energy. 
Overall, China's energy consumption growth is sub-health, remains dependent on oil consumption and coal consumption on the high side, Must pay attention to and accelerate the use of natural gas, nuclear energy and renewable energy.

\section{Forecast of China's total energy consumption and coal consumption}

Now Consider, China's total energy consumption and coal consumption evaluation system is a Grey system, And many influence factors, This article will use the Grey forecasting model GM $(1,1)$ make prediction research。

\section{GM $(1,1)$ Model}

GM $(1,1)$ Model is 1 order equations 1 variables Grey Model, Hypothesis: $\mathrm{n}$ observation value of the original data set of the sequence $X^{(0)}$ is: $X^{(0)}=\left\{X^{(0)}(1), \ldots, X^{(0)}(n)\right\}$.

The basic steps of GM $(1,1)$ model:

Step1. Through the accumulation generation new sequence $X^{(1)}(k)=\sum_{m=1}^{k} X^{(0)}(m)$;

Step2. Structure accumulate matrix B and constant term vector $Y_{n}$;

Step3. Using least square to solving the estimated parameters vector $\hat{\alpha}=\left(B^{T} B\right)^{-1} B^{T} Y_{n}$ 即 $\hat{\alpha}=\left(\begin{array}{l}a \\ b\end{array}\right)$;

Step4. Will Grey parameters go into Whitenization differential equations:

$$
\frac{d X^{(1)}}{d t}+a X^{(1)}=b
$$

Step5. Solving differential equation to obtain time response and forecast model.

$$
\text { Time response : }\left\{\begin{array}{l}
\hat{X}^{(1)}(k+1)=\left(X^{(0)}(1)-\frac{b}{a}\right) e^{-a k}+\frac{b}{a} \\
X^{(0)}(1)=X_{0}, \quad \frac{b}{a}=k_{0}
\end{array}(\mathrm{k}=0,1,2, \ldots, \mathrm{n})\right.
$$

Forecast model: $\hat{X}^{(1)}(k+1)=\left(X_{0}-k_{0}\right) e^{-a k}+\mathrm{k}_{0} ;$

Step6. The model test and forecast

Method 1. Residual inspection (table 2)

Table 2 GM (1, 1) Model Residual Inspection

\begin{tabular}{cccc}
\hline Observation value & Fitted Value & Residual error & Relative error \\
\hline$X^{(0)}(k), \mathrm{k}=1 \ldots \mathrm{n}$ & $\hat{X}^{(0)}(k), \mathrm{k}=1 \ldots \mathrm{n}$ & $\varepsilon(k)=X^{(0)}(k)-X^{(0)}(k)$, & $\Delta_{k}=\frac{|\varepsilon(k)|}{X^{(0)}(k)}$ \\
& & $\mathrm{k}=1 \ldots \mathrm{n}$ & $\mathrm{k}=1 \ldots \mathrm{n}$ \\
\hline
\end{tabular}

Method 2. Mean square error ratio and Small error probability inspection

$$
\mathrm{C}=\frac{\mathrm{S}_{2}}{\mathrm{~S}_{1}}, P=p\left\{\left|\Delta^{(0)}(i)-\bar{\Delta}^{(0)}\right|<0.6745 S_{1}\right\}, S_{1}=\sqrt{\frac{\sum\left[X^{(0)}(i)-\bar{X}^{(0)}\right]^{2}}{n-1}}, S_{2}=\sqrt{\frac{\sum\left[\Delta^{(0)}(i)-\bar{\Delta}^{(0)}\right]^{2}}{n-1}}
$$

Here $\mathrm{C}$ is Mean square error ratio, $\mathrm{P}$ is Small error probability.

According to the Grey forecasting theory, when $\mathrm{P}>0.95$ and $\mathrm{C}<0.35$, Model is very reliable for level I; when $\mathrm{P}>0.8$ and $0.35<\mathrm{C}<0.5$, Model is reliable for level II; when $\mathrm{P}>0.7$ and $0.5<\mathrm{C}<0.65$, Model is reliable for level III.

\section{Forecasts of China's total energy consumption and coal consumption}

If 19 years from 1996 to 2014 in China's total energy consumption (see table 1), Using GM $(1,1)$ model to predict the total energy consumption in China, from 2015 to 2018 were respectively 502615.2, 540326.8, 580868, 624451, 671304, China's total energy consumption will be sustained and rapid rise significantly, Is too high, This does not accord with China for nearly five years 
development clearly. Its reason, because of the extensive economic growth since China's reform and opening up. China's "twelfth five-year" (2011-2015), since the Chinese economy into the new normal, Shift and slow economic growth, Energy consumption appear new changes during this period, Therefore need to be on the basis of $2011 \sim 2014$ in China's energy consumption and coal consumption data (see table 3 ) to predict will become more scientific, Use the GM $(1,1)$ model, we predicts $2015 \sim 2019$ China's total energy consumption and coal consumption index.

Here the original series $X^{(0)}$ represent for China's energy consumption and coal consumption index, data see table 3 .

Table 3 China's energy consumption and coal consumption data Unit: ten thousand tons of standard coal

\begin{tabular}{|c|c|c|c|c|}
\hline index & 2011 & 2012 & 2013 & 2014 \\
\hline China's energy consumption & 387043 & 402138 & 416913 & 426000 \\
\hline coal consumption & 271704 & 275465 & 280999 & 280060 \\
\hline
\end{tabular}

Data sources: The national bureau of statistics, the total energy consumption and composition in 2011-2014 communique

According to the data table 3, The following results is obtained by using Data processing system

(DPS) ( GM ( 1,1$)$ model ), respectively.

\section{The forecast analysis of China's total energy consumption}

The output of DPS is

Model parameters:

$a=0.028681, \mathrm{~b}=386290$

$\mathrm{x}(\mathrm{t}+1)=13855685 \mathrm{e}^{0.028681 \mathrm{t}}-13468642.27$

Table 4 Residual Inspection of China's total energy consumption index

\begin{tabular}{ccccc}
\hline No. & $\begin{array}{c}\text { Observation } \\
\text { value }\end{array}$ & Fitted Value & Residual error & Relative error \\
\hline X( 2) & 402138 & 403144.2 & -1006.257 & -0.25023 \\
X( 3) & 416913 & 414874.1 & 2038.879 & 0.48904 \\
X( 4) & 426000 & 426945.2 & -945.275 & -0.22190 \\
\hline
\end{tabular}

The evaluation of the Model:

$\mathrm{C}=0.096<0.35, \mathrm{P}=1.0000>0.95$, Model is very reliable for level I.

The future five time prediction:

$\begin{array}{ll}\mathrm{X}(\mathrm{t}+1)= & 439367.65 \\ \mathrm{X}(\mathrm{t}+2)= & 452151.47 \\ \mathrm{X}(\mathrm{t}+3)= & 465307.24 \\ \mathrm{X}(\mathrm{t}+4)= & 478845.796 \\ \mathrm{X}(\mathrm{t}+5)= & 492778.267\end{array}$

Qmin=-1006.25703

Conclusion: Predictive values of 2015、2016、2017、2018、2019 China's total energy consumption index is 439367.65、452151.47、465307.24、478845.796、492778.267, respectively, China's total energy consumption will continue to rise, slowly to predict more objectively.

\section{The forecast analysis of coal consumption}

The output of DPS is

Model parameters:

$a=0.010166, \quad \mathrm{~b}=272207.67$

$\mathrm{x}(\mathrm{t}+1)=27048587.37 \mathrm{e}^{0.010166 \mathrm{t}}-26776883.368$

Table 5 Residual Inspection of coal consumption index

\begin{tabular}{ccccc}
\hline No. & $\begin{array}{c}\text { Observation } \\
\text { value }\end{array}$ & Fitted Value & Residual error & Relative error \\
\hline X( 2) & 275465 & 276372.1 & -907.1389 & -0.329312 \\
X( 3) & 280999 & 279196.0 & 1802.996 & 0.641638 \\
X( 4) & 281160 & 282048.7 & -888.722 & -0.316091 \\
\hline
\end{tabular}

The evaluation of the Model:

$\mathrm{C}=0.3202<0.35, \mathrm{P}=1.0000>0.95$, Model is very reliable for level I. 
The future five time prediction:

$\begin{array}{ll}X(t+1)= & 284930.59 \\ X(t+2)= & 287841.9 \\ X(t+3)= & 290782.96 \\ X(t+4)= & 293754.068 \\ X(t+5)= & 296755.535 \\ \text { Qmin }=-907.13893\end{array}$

Conclusion: Predictive values of 2015、2016、2017、2018、2019 China's total energy consumption index is 284930.59、287841.9、290782.96、293754.068、296755.535, respectively, China's coal consumption will continue to slowly rising. The prediction results and the economic up state, the supply side, and much starker choices-and graver consequences-in 6\% GDP growth target is adapted.

\section{Acknowledgements}

This work was financial support by Top-notch Academic Programs Project of Jiangsu Higher Education Institutions (TAPP).

\section{References}

[1] Wei-guo Wang etc.: The influence factors of China's total energy consumption, The practice of mathematics and understanding,9 (2014) p.97-107.( In Chinese)

[2] S.F.Liu, S.M.Xie: The Grey system theory and its application (fifth edition), Science Publising, Beijing (2008). ( In Chinese)

[3] G.Wang, M.S.Wang: Modern mathematical modeling method, Science Publising, Beijing (2010).

[4] JIANG Yong, Jiangsu Environmental Science and Technology, Vol. 20(2007), p. 57. ( In Chinese)

[5] G.Wang, Advanced Materials Research, Vol. 361-363 (2012) p.1673-1678

[6] Data Information on http://data.stats.gov.cn/tablequery.htm?code=AD0H 